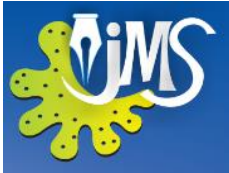

\title{
Model-Based Analysis of International Tourist Flow to Sri Lanka
}

\author{
K M U B Konarasinghe \\ Institute of Mathematics and Management (Pvt) Ltd ,Nugegoda, Sri Lanka
}

\begin{abstract}
Sri Lanka entered the international tourism market in the late 1960s. Forecasting of international tourist arrivals to Sri Lanka is immensely important and it's a timely requirement. Hence, finding the most appropriate forecasting technique is essential. In view of the above, objective of the study is to forecasting international tourism flows to Sri Lanka. Annual data on arrivals obtained from annual statistical report 2013 of Sri Lanka Tourist Development Authority from 1968 to 2013. Moving Average smoothing model, Single Exponential Smoothing (SES) model and Double Exponential Smoothing (DES) models are tested on monthly arrivals. The best fitting model was selected by comparing Mean Absolute Percentage Errors (MAPE). Results revels that the single Moving Average of order 2 (MA 2) model has the least MAPE which is 19\%. SES of Alpha 0.9 has the least MAPE which is 17\%.But the residuals were not normally distributed. Double Exponential of Alpha 0.8, Beta 0.9 and Alpha 0.9, Beta 0.9 has the least MAPE which is 17\%. In these model residuals were normally distributed. Double Exponential of Alpha 0.8, Beta 0.9 and Alpha 0.9, Beta 0.9 are the suitable models for forecasting international tourist arrivals to Sri Lanka. Smoothing techniques can be used only for forecasting one period ahead. Therefore, it is recommended to test various trend models on forecasting tourist arrivals.
\end{abstract}

KEYWORDS: Smoothing techniques, MAPE, Double Exponential Smoothing. 


\section{INTRODUCTION}

Tourism can be recognized as long as people have travelled. Tourism as "the temporary movement of people to destinations outside their normal places of work and residence, the activities undertaken during their stay in those destinations, and the facilities created to cater to their needs (Mathieson \& Wall, 1982 ).

The World Tourism Organization defines tourist as" a person who travels to and stays in places outside his usual place of residence for more than twenty-four (24) hours and not more than one consecutive year for leisure, business and other purposes not related to the exercise of an activity remunerated from within the place visited" (WTTOIHR, 1999). Sri Lanka entered the international tourism market in the late 1960s. Over the past years international tourism in Sri Lanka has shown growth in two ways; growth of volume and value (SLTDA, 2013).

\subsection{Research Problem}

The need for accurate forecasts of international tourist arrivals facilitates for decisions at all levels, from government to a single tourist business in the tourism industry planning at all levels imperative due to the perishable nature of the tourism products such as plane seats, hotel rooms etc. cannot be inventoried (Jackman \& Lorde, 2009). Modeling international tourist arrivals is an essential allocation of resources, facility management and demand management in any destination. Under these circumstances forecasting of international tourist arrivals to Sri Lanka is immensely important and it's a timely requirement. Hence, finding the most appropriate forecasting technique is essential. In view of the above, objective of the study is to modeling international tourism flows to Sri Lanka.

\section{METHODOLOGY}

Annual arrival data utilized from 1968 to 2013 obtained from the annual report 2013. Descriptive Statistics, Moving average techniques and Exponential smoothing techniques, and are tested on annual arrivals. The best fitting model was selected by comparing Mean Absolute Percentage Errors (MAPE);

$M A P E=\frac{1}{n} \sum\left|\left(\frac{Y_{t}-F_{t}}{Y_{t}}\right) \cdot 100\right|$

Where; $Y_{t}=$ Observed value of time $t, F_{t}=$ Forecasted value of time $t$

\subsection{Moving Average (MA) smoothing models}

Moving Average (MA) smoothes data by averaging consecutive observations in a series and provides short-term forecasts.

$$
\begin{aligned}
& F_{t+1}=\frac{1}{n}\left(Y_{t}+Y_{t-1}+\cdots+Y_{t+1-n}\right) \\
& F_{t+1}=\frac{1}{n} \sum_{i=t+1-n}^{t} Y_{i}
\end{aligned}
$$

Where; $Y_{t}=$ Observed value of time $t, F_{t}=$ Forecasted value of time $t$

\subsection{Single Exponential Smoothing Models}

Single exponential smoothing smoothes data by computing exponentially weighted averages and provides short-term forecasts.

$F_{t+1}=\alpha Y_{t}+(1-\alpha) F_{t}$

Where,

$\mathrm{Yt}=$ observed value for time period $\mathrm{t}, \mathrm{Ft}=$ fitted value for time period $t, \alpha=$ weighting factor

\subsection{Double exponential smoothing models}

Double exponential smoothing provides short-term forecasts (Holt, 1957). This procedure can work well when a trend is present, but it can also serve as a general smoothing method. Formulae of double smoothing technique are;

$$
\begin{aligned}
& S_{t}^{\prime}=\alpha Y_{t}+(1-\alpha) S_{t-1}^{\prime} \\
& S_{t}^{\prime \prime}=\alpha S_{t}^{\prime}+(1-\alpha) S_{t-1}^{\prime \prime} \\
& a_{t}=2 S_{t}^{\prime}-S_{t}^{\prime \prime}
\end{aligned}
$$




$$
\begin{aligned}
& b_{t}=\frac{\alpha}{1-\alpha}\left(S_{t}^{\prime}-S_{t}^{\prime \prime}\right) \\
& F_{t+m}=L_{t}+b_{t} m
\end{aligned}
$$

Where S' and S' are single and double smoothed values respectively. $a_{t}$ is the smoothed value at the end of period $t, b_{t}$ is the estimated trend at the end of period $t$, and $\mathrm{m}$ is the forecast horizon.

\section{RESULTS}

Data analysis consists three parts,

\subsection{Descriptive Statistics}

3.2. Testing MA models.

3.3. Testing Exponential smoothing models.

(a) Single Exponential Smoothing.

(b) Double Exponential Smoothing.

All the models were tested for annual arrival data from 1968 to 2013. Among each model type, the best fitting model was selected by comparing MAPE'S. Time series plot of international tourist arrivals [Error! Reference source not found.], obtain for the period 19682013. According to [Error! Reference source not found.], there is an increasing of international tourist arrivals from 1968 to 1983 and decrease up to 1990.The fluctuations of the arrivals are constant from Year 1990 to 2000. There is an increasing of the fluctuations can be seen within the period of Year 2000 to 2009. After 2009 there was a dramatic improvement reported.

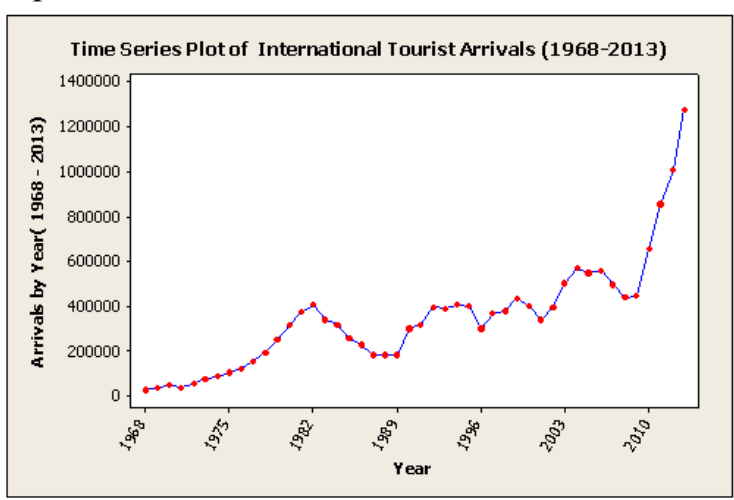

Figure 1. International Tourist Arrivals

\subsection{Descriptive Statistics}

Descriptive results revel from (Figure 2) emphases that mean arrivals are 351190. First quartile shows that $25 \%$ of the tourist arrivals are at most 182652 , median shows that $50 \%$ of the tourist arrivals are at most 337162, and third quartiles show that $75 \%$ of the tourist arrivals are at most 436949. The distribution of the international tourist arrivals is not normally distributed but the distribution is positively skewed. Box and whisker plot shows three outliers; they are the arrivals of year 2011, 2012 and 2013.In general outliers have to be removed in further analysis, but these were not removed, because (Figure 1) shows a clear boom in arrivals after 2010.

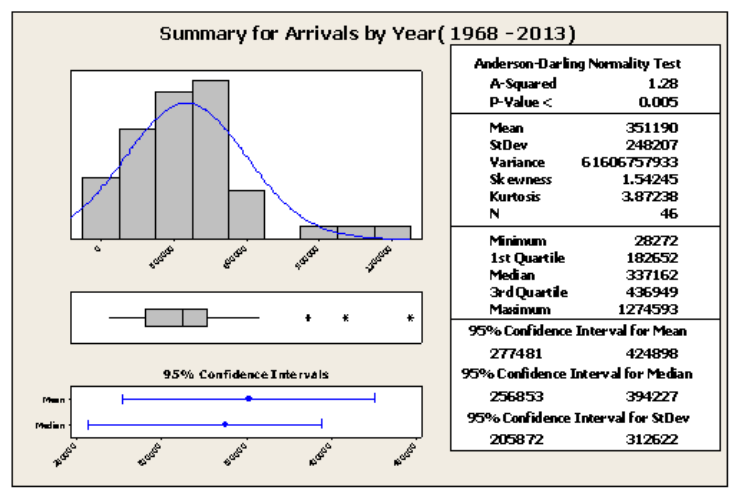

Figure 2. Summary of Arrivals by Year 3.2. Testing Moving Average Models

Table 1. Summary of Moving Average Models.

\begin{tabular}{|c|c|c|}
\hline $\begin{array}{c}\text { Single } \\
\text { Moving }\end{array}$ & MAPE & Normality of Residuals \\
\hline MA 2 & 19 & No \\
\hline MA 3 & 22 & No \\
\hline $\begin{array}{c}\text { MA } \\
(2 * 2)\end{array}$ & 23 & No \\
\hline $\begin{array}{c}\text { MA } \\
(3 * 2)\end{array}$ & 22 & No \\
\hline
\end{tabular}

Among the above models shown in table 1 , a single moving average of order 2 (MA 2) model 85 
has the least MAPE which is $19 \%$.But Residuals are not normally distributed. Considering the best fitting moving average model is;

$$
F_{t+1}=\frac{1}{n}\left(Y_{t}+Y_{t-1}\right)
$$

\subsection{Testing Exponential Smoothing Models.}

\section{(a) Single Exponential Smoothing (SES) models}

Various SES models were tested for different alpha values and residuals of each model were tested for normality. Table 2 shows the summary of part of the output.

Table 2. Summary of Single Exponential Smoothing Models

\begin{tabular}{|c|c|c|}
\hline $\boldsymbol{\alpha}$ & MAPE & $\begin{array}{c}\text { Normality of } \\
\text { Residuals }\end{array}$ \\
\hline 0.6 & 20 & No \\
\hline 0.7 & 19 & No \\
\hline 0.8 & 18 & No \\
\hline 0.9 & 17 & No \\
\hline
\end{tabular}

Among the above models, SES of Alpha 0.9 has the least MAPE which is $17 \%$.But the residuals were not normally distributed. Accordingly the best fitting SES model is;

$$
F_{t+1}=0.9 Y_{t}+0.1 F_{t}
$$

\section{(b) Double Exponential Smoothing}

Various Double Exponential models were tested for different alpha and beta values and residuals of each model were tested for normality. Table 3 shows the summary of part of the output. Among the above models Double Exponential of Alpha 0.8, Beta 0.9 and Alpha 0.9, Beta 0.9 has the least MAPE which is $17 \%$.In theses models residuals were normally distributed.

Table 3. Summary of Double Exponential Smoothing

\begin{tabular}{|c|c|c|c|}
\hline $\boldsymbol{\alpha}$ & $\boldsymbol{\beta}$ & MAPE & $\begin{array}{c}\text { Normality of } \\
\text { Residuals }\end{array}$ \\
\hline
\end{tabular}

\begin{tabular}{|l|l|l|l|}
\hline 0.6 & 0.3 & 20 & Yes \\
\hline 0.6 & 0.9 & 19 & Yes \\
\hline 0.7 & 0.9 & 18 & Yes \\
\hline 0.8 & 0.9 & 17 & Yes \\
\hline 0.9 & 0.9 & 17 & Yes \\
\hline
\end{tabular}

Figure 3 Represents the residual plots of one of the best Double Exponential model among those two. Histogram of the (Figure 3) shows, the shape of the distribution of residuals. It is symmetrical. Normal probability plot of residuals and Anderson Darling test confirm that residuals are normally distributed. The graph of residual versus fitted values shows that they are correlated. The plot of the residuals versus order of the data shows residuals are non random. Therefore Double Exponential of Alpha 0.8 , Beta 0.9 and Alpha 0.9 ,Beta 0.9 are the best fitting models for forecasting international tourist arrivals to Sri Lanka



Figure 3. Residual Plot of Arrivals by Year

\section{CONCLUSION AND FURTHER WORK}

Forecasting international tourism flows to Sri Lanka is the objective of the study. Annual arrival data from 1968 to 2013 utilized. Descriptive statistics obtained under first step and results revels that mean arrivals are 351190 . First quartile shows that $25 \%$ of the tourist arrivals are at most 182652 , median shows that $50 \%$ of the tourist arrivals are at most 337162 , and third quartiles show that $75 \%$ of them are at most 436949. The distribution of the international tourist arrivals is not normally distributed but the distribution is positively skewed. Descriptive statistics obtained under first step. Moving average techniques and exponential 
smoothing techniques methods are tested on annual arrivals. The best fitting model was selected by comparing MAPE's. A Single moving average of order 2 (MA 2) model has the least MAPE which is $19 \%$.But Residuals are not normally distributed.SES of Alpha 0.9 has the least MAPE which is $17 \%$.But the residuals were not normally distributed. Double Exponential of Alpha 0.8, Beta 0.9 and Alpha 0.9, Beta 0.9 has the least MAPE which is $17 \%$.In theses models residuals were normally distributed. Therefore Double Exponential of Alpha 0.8, Beta 0.9 and Alpha 0.9, Beta 0.9 are the suitable models for forecasting international tourist arrivals to Sri Lanka. MAPE of selected models was satisfactory. But smoothing techniques can be used only for forecasting one period ahead. It is a clear disadvantage in long term planning and forecasting, therefore it is recommended to test various trend models on forecasting tourist arrivals.

\section{REFERENCES}

HOLT CC. Forecasting seasonal and trends by exponentially weighted moving average. Office of Navel Research. Research memorandum 1957;52.

JACKMAN M. \& LORDE T. Modeling and forecasting tourist flows to Barbados using seasonal univariate time series models. 2009.

MATHIESON A \& WALL G. Tourism: Economic, physical, and social impacts. London and New York, Longman. 1982.

SRI LANKA TOURISM DEVELOPMENT AUTHORITY (SLTDA). Available from: http://www.sltda.lk/sites/default/files/Annual_St atistical_Report_2013.pdf (accessed_on 02.04.2014).

WORLD TRAVEL AND TOURISM ORGANIZATION AND INTERNATIONAL HOTEL AND RESTAURANT (WTTOIHR). The global importance of tourism. Commission on Sustainable Development, seventh session, New York. 1999. 